\title{
Hypertension in young patients: at what age should we explore?
}

\author{
M. Tougorti, F. Chaker, M. Yazidi, I. Cherif, M. Chihaoui, O. Rejeb, H. Slimane \\ Endocrinology department, Rabta Hospital, Faculty of medicine, Tunis, Tunisia
}

Introduction

e High blood pressure is commonly related to either endocrine causes or kidney damage in young patients. In recent years, hypertension has been increasing as well as the other components of metabolic syndrome such as obesity and diabetes. The aim of this study was to determine the etiology of hypertension in patients aged less than 40 years old.

\section{Materials and methods}

eIt was a retrospective study including 55 patients less than 40 years old hospitalized in the endocrinology department between 2003 and 2015 for a high blood pressure. Patients with cardiac or known renal failure were not enrolled.

e Epidemiological characteristics, clinical signs of secondary hypertension and biological data were recorded.

\section{Results}

( The mean age at diagnosis of hypertension was $27.7 \quad 7.4$ years.

c Sex ratio (M/F) was 1.2 .

eThe mean duration of hypertension was 2.13 .59 years

Figure 1: Hypertension etiologies in young patients

@There was a family history of hypertension in $72.7 \%$ of cases.

e Twenty percent patients had prediabetes or diabetes, $30.9 \%$ had dyslipidemia and $81.8 \%$ had overweight.

e Endocrine causes of hypertension were found in $25.5 \%$. (Figure 1 )

e Primary hyperaldosteronism was diagnosed in 8 cases (14.54\%):

Six Conn syndrome and two adrenal hyperplasia (Figure 2)

c Secondary hyperaldosteronism was found in 2 cases $(3.6 \%)$

@ Renal artery ultrasound was performed in $47.2 \%$ of cases. No renal artery stenosis was diagnosed.

e One patient had an hypoplasia of thoracic aorta $(1.81 \%)$

@The etiology of hypertension remained unknown in $70.9 \%$ of cases.

c the rate of overweight, pre-diabetes and dyslipidemia was

similar between the patients with secondary hypertension and those with hypertension without known etiology (Table 1)

\begin{tabular}{|l|c|c|c|}
\hline $\begin{array}{c}\text { Secondary } \\
\text { hypertension }\end{array}$ & $\begin{array}{c}\text { Other causes of } \\
\text { hypertension }\end{array}$ & P \\
\hline Diabetes(\%) & 76.92 & 83.87 & 0.58 \\
\hline Overweight (\%) & 73.33 & 89.47 & 0.11 \\
\hline Dyslipidemia(\%) & 66.66 & 59.37 & 0.65 \\
\hline
\end{tabular}

Table 1: Metabolic syndrome components and hypertension in young patient

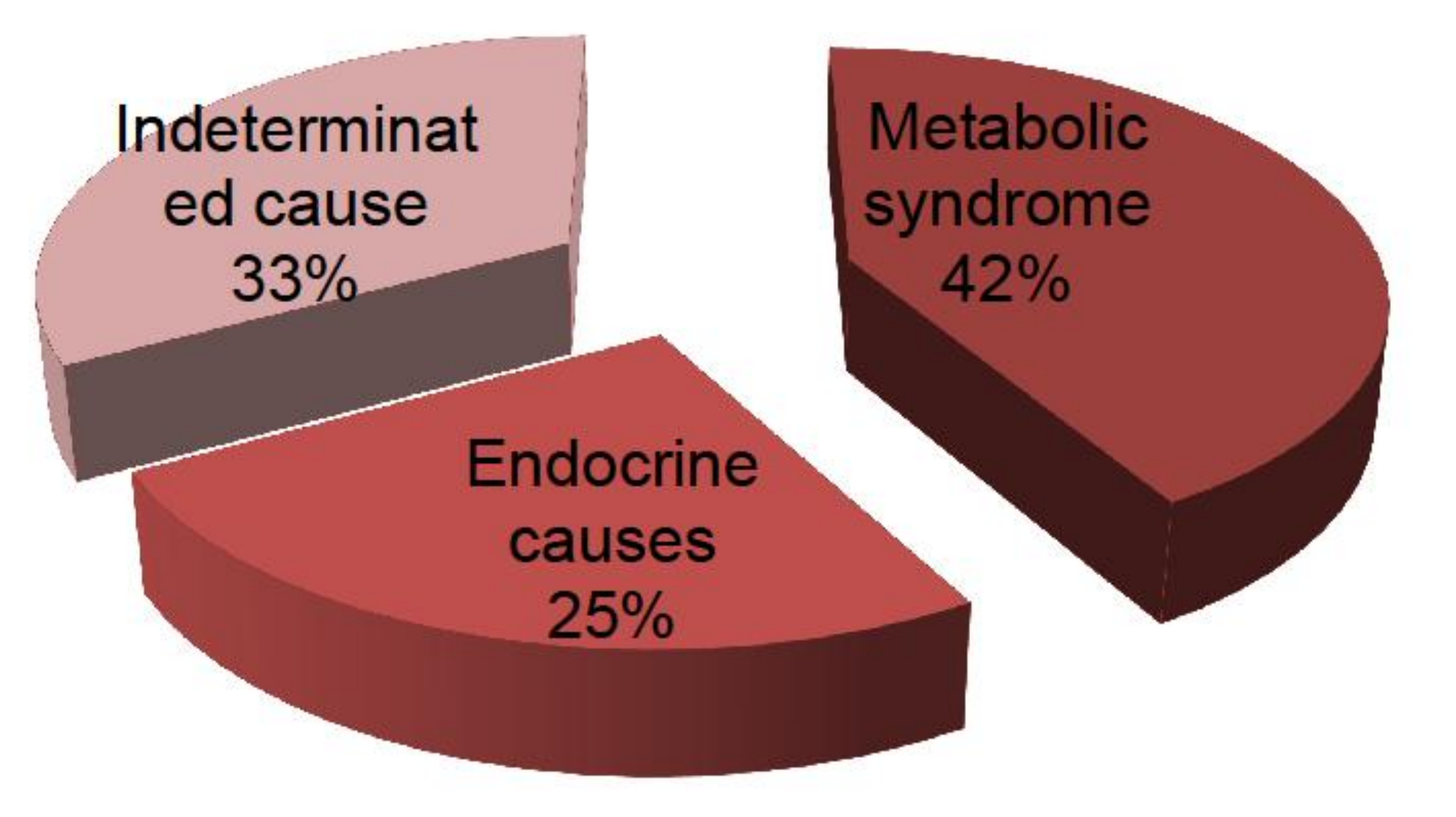

- Figure 2: Endocrine causes of hypertension

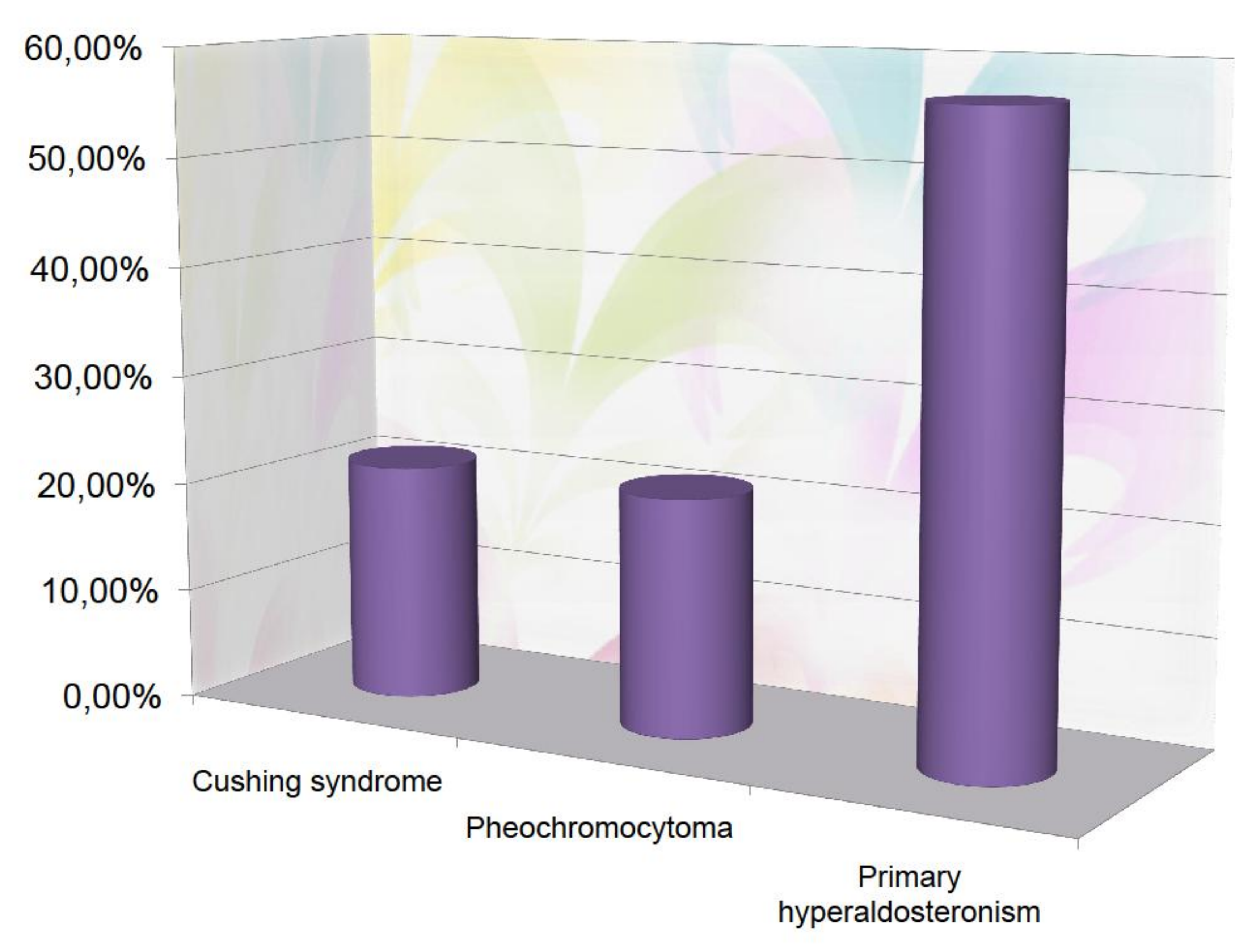

\section{Discussion et conclusion}

eHypertension in young patients is defined as every patient suffering from high blood pressure aged less than 30 years old (1)

( In our study, such as many recent studies, investigations for hypertension usually are performed in case of clinical or biological settings and for patients aged less than 40 years.(2)

e Renovascular, renal parenchymal diseases and endocrine hypertension accounts for up to $15-20 \%$ of hypertension's causes (3).

e In our study, patients with renal failure were excluded. Endocrine etiology was incriminated in $25.5 \%$ of cases. This prevalence may be due to selection bias. No renal artery stenosis was found but renal artery ultrasound was performed in less than $50 \%$ of cases.

ePrimary hyperaldosteronism was the most frequent cause of endocrine etiology of hypertension (2)(3)

eIn our study incidence of overweight, dyslipidemia and diabetes was not significantly different between patients with secondary hypertension and patients with hypertension secondary to metabolic syndrome or to an undeterminated causes. That's why hypertension in obese patient shouldn't dispense of the exploration of secondary hypertension in young patient.

References:

(1) 2005. Haute Autorité de santé.

(2) C NOILHAN ET al. HTA du sujet jeune dans un service spécialisé en HTA. Anales de cardiologie et d'angéiologie 64(2015),S3-S22.

(3) Raluca TRIFANESCU ET al Screening for Secondary Endocrine Hypertension in Young Patients Maedica (Buchar). 2013 Jun; 8(2): 108-115. 